\title{
Investigation about Influence of Product Methods and Different Cores on Buckling and Post Buckling Behaviors of Sandwich Panels
}

\author{
Sam Barati Nardin ${ }^{1, *}$, Javad Rabiee Ezbarami ${ }^{2}$, Reza Fazeli ${ }^{3}$ \\ ${ }^{1}$ Naval Architecture, Head of ASAK CO., Marine Department, Tehran, Tehran, Iran \\ ${ }^{2}$ Applied Chemistry, Material Lab, South Tehran University, Tehran, Tehran, Iran \\ ${ }^{3}$ Physical Chemistry, Director of Basic Science Faculty, South Tehran University, Tehran, Tehran, Iran
}

Copyright $\mathrm{C} 2018$ by authors, all rights reserved. Authors agree that this article remains permanently open access under the terms of the Creative Commons Attribution License 4.0 International License

\begin{abstract}
Despite of laminate or sandwich composite materials structure, mechanical behavior can estimate by methods or analytical relations like laminates classical theory according factors just like mechanical properties, fiber percentage, and product methods and etc. but generally these estimates are far from experimental results. This paper investigates about influence of product methods and different cores on buckling and post buckling behaviors of sandwich panels. Each panel was built by to quit different product method, hand layup or vacuum bag infusion procedure with different core. To build the panels an effort had made to choice materials which have usage in marine industry, special for high speed boats. Sandwich panels have $150 \times 450 \mathrm{~mm}^{2}$ dimensions and one simply support and one clamed support. After tests, numerical models results which drive from finite element software are compared with experimental data. The results represent that combined model is suitable for simulate buckling and post buckling behavior. After chosen the software model, different parameters were evaluated whom the link element has the most efficacy on numerical results.
\end{abstract}

Keywords Sandwich Panels, Buckling Strength, Post-Buckling Behavior, Hand Layup Method, Vacuum Bag Infusion Procedure, Load Controlled Method, Displacement Controlled Method

\section{Introduction}

Marine industry is developing very fast just like other industries. Increasing marine transports, vessels speed ultimate etc. which engineers have to use optimum product methods and materials with lighter weight. Because of increasing size, speed and reducing ship's body, engineers just think about different materials like composites with goals as mentioned. These materials are used in vessels (and surly in other marine structures) abundance as laminate or sandwich panel structures.

On the other hand any different loads for example buoyancy force, waves and dead weight loads incur to vessel's body, so vessel's structure must be pass local and global analysis. One of these category loads that occur in body is inplane loads. These loads are created by many factors, which global body deformation in hogging and sagging is the major of them. With appearing hogging, sagging and inplane loads, investigate buckling and post buckling behavior in sandwich panels that used in vessels structure might be essential. Despite of laminate or sandwich composite materials structure, mechanical behavior can estimate by methods or analytical relations like laminates classical theory according factors just like mechanical properties, fiber percentage, and product methods and etc. but generally these estimates are far from experimental results.

On the other hand, almost classification societies prefer to use experimental equations instead of laminate classic theory. In this regard, mostly classification societies to evaluate the accuracy of experimental equations or improve their accuracy level demand some tests about composite structures specimens that used in vessels body. It's important to note that because of mechanical property and elements behaviors aren't complicated, identity of mechanical behavior which mentioned before, is one of research lacks. Hence, studies that have done about this field, can debate in three branches: analytical studies, experimental studies and numerical studies.

\subsection{Analytical Researches}

M. Yamanaka and their associates (2017) studied about Elastic buckling behavior of the surface material in sandwich structure. Sandwich structure manufactured 
using a thin plate is lightweight, but has high bending stiffness. The purpose of this study is to understand the tendency of elastic buckling strength of the steel sandwich panel under out-of-plane bending and evaluate it using a simple formula [1]. M. Abouhamzeh and M. Sadighi (2016) studied on Buckling optimization of sandwich cylindrical panels. A finite element program is developed in MATLAB to solve the governing differential equations of the global buckling of the structure. In order to find the optimal solution, the genetic algorithm Toolbox in MATLAB is implemented. Verifications are made for both the buckling finite element code and also the results from the genetic algorithm by comparisons to the results available in literature. Results are presented in terms of stacking sequence of fibers in the face sheets and core to face sheet thickness ratio [2]. Z. Tang and their associates (2015) studied about buckling of axially loaded sandwich composite panels with reinforced calcium silicate faces and polyurethane cores. In order to predict the global buckling load of sandwich panels subjected to axial loads, the buckling formulae are theoretically derived and suggested in design. Using the method of effective length factor, both buckling formulae for fixed-fixed sandwich panel and hinged-hinged one are unified into the same form. The buckling formulae are verified by axial load tests, finite element (FE) software ABAQUS. The accuracy degree of theoretical result in hinged condition is mainly affected by length and initial geometric imperfection. The variation of core shear modulus has little effect on error [3]. Evan Pineda and their associates (2014) studied about Buckling Testing and Analysis of Honeycomb Sandwich Panel Arc Segments of a Full-Scale Fairing Barrel: Comparison of In and Out of Autoclave Face sheet Configurations. Four honeycomb sandwich panels, representing 1/16th arc segments of a $10 \mathrm{~m}$ diameter barrel section of the Heavy Lift Launch Vehicle, were manufactured and tested under the NASA Composites for Exploration and the NASA Constellation Ares V programs. To improve the robustness of the geometrically nonlinear finite element model, measured surface imperfections were included in the geometry of the model. Both the linear and nonlinear models yielded good qualitative and quantitative predictions. Additionally, it was correctly predicted that the panel would fail in buckling prior to failing in strength. Furthermore, several imperfection studies were performed to investigate the influence of geometric imperfections, fiber angle misalignments, and three-dimensional effects on the compressive response of the panel [4].

P. Jeyakrishnan and their associates (2013) studied on buckling of honeycomb sandwich panel of hexagonal cell has been carried out by considering simply supported boundary constraints explicitly. A novel theoretical formulation has been developed for the buckling of honeycomb panel as per Mil Standard (MIL-HDBK-23A). The laminate element type has been considered for linear static analysis using Lanczos Method (finite element method (FEM)). The buckling analysis carried out by FEM has been compared and validated with theoretical and experimental investigation for different panel aspect ratio under static load [5]. W. Ji and A. M. Waas (2012) had research about exactly calculation loading onto buckling in sandwich panels with orthotropic elastic shell and core. In this activity inplane load results compared with finite element method [6]. B. K. Hadi and F. L. Matthews (2001) studied about global buckling sandwich panels with simply support that contained a hole. They introduce a method to determined global buckling load and compared that with others predictions. At least the answer from this method has suitable accuracy for panels contained a hole with diameter less 30\% panel width [7]. B. K. Hadi and F. L. Matthews (1998) worked about estimating buckling load in anisotropic sandwich panels. They presented procedure to calculate buckling load in sandwich panels according to Zig-Zag displacement and transverse shear deflection models. In this activity the models were checked for surface arrangement and ratio [8]. M. Header (1991) with energy method, different boundary conditions, using failure functions earn the results and compared those with numerical methods. This procedure had acceptable out coming for specimen with length per width ratio equal one or more [9].

\subsection{Experimental Researches}

E. J. Pineda and their associates (2014) studied about Buckling Testing and Analysis of Honeycomb Sandwich Panel Arc Segments of a Full-Scale Fairing Barrel. In this activity four honeycomb sandwich panels, representing $1 / 16$ th arc segments of a $10 \mathrm{~m}$ diameter barrel section of the heavy lift launch vehicle, were manufactured under the NASA Composites for Exploration program and the NASA Constellation Ares V program. Two configurations were chosen for the panels: 6-ply face sheets with $1.125 \mathrm{in}$. honeycomb core and 8-ply face sheets with $1.000 \mathrm{in}$. honeycomb core. Additionally, two separate carbon fiber/epoxy material systems were chosen for the face sheets. This manuscript summarizes the experimental and analytical modeling efforts pertaining to the panel composed of 8-ply. To improve the robustness of the geometrically nonlinear finite element model, measured surface imperfections were included in the geometry of the model. Additionally, it was predicted correctly that the panel would fail in buckling prior to failing in strength [10]. M. A. Wadee and their associates (2010) studied on sandwich struts with different cores. In this activity analytical models compared with geometric nonlinear conclusions due to elicitation equation for struts buckling. In analytical activity, Timoshenko Beam Theory \& Reddy-Bickford Beam Theory is used. The specimens with $154 \times 77 \mathrm{~mm}^{2}$ and $102 \times 77 \mathrm{~mm}^{2}$ dimensions were tested while their width had clamped and their length had simply supports. Twelve panels which made by VERMIT method 
were tested [11]. M. P. Boyle and their associates (2001) studied on buckling and post buckling onto square orthotropic sandwich panels. There were two groups with $183 \times 92 \mathrm{~cm}^{2}$ and $122 \times 92 \mathrm{~cm}^{2}$ dimensions and balsa and P.V.C. cores that made by VERMIT method and their length per width ratio were 1.3 and 2 . The loads applied on their width [12].

\subsection{Numerical Researches}

S. B. Nardin and their associates (2014) studied buckling and post buckling about sandwich panels with special layers. The specimens had built without mat layers, many FEM models created due to determined which how far the test data had far from numerical models [13]. M. Gaiotti and C. M. Rizzo (2012) studied about sandwich panels buckling that used in marine industry. Numerical models were compared with experimental specimens. The result was helped to buckling analysis for modifies vessels design [14]. F. Alives and L. A. Carlsson (2007) worked on buckling and debonding sandwich panels under pressure inplane load. Nonlinear finite element method for predict debonding core in a panel under pressure load that contain a circle shape hole at the center of panel was used. A 3D finite element model of sandwich panel with linear elastic structure was spread for determines stress and energy factors vertical or horizontal to load direction [15]. Vinod P. Veedu and Leif A. Carlsson (2005) studied on columns buckling with numerical methods and investigated on debonding. Linear and nonlinear finite element methods were done for buckling and collapse behavior for sandwich column with soft core. In this analysis, deboned length and core densities were tested. The results showed that less densities and more debonding reduce buckling load. Buckling load according linear finite element method was more than buckling load according nonlinear finite element method. Predicting models with sandwich contain vinyl ester laminate and different cores compare with experimental tests. Buckling load predictions were similar with experimental tests [16].

P. Gaudenzi and their associates (2001) studied on post buckling of sandwich panels before delamination under inplane load. A Corrigendum for continues increases method in damaged composite nonlinear behavior in delamination position was presented [17].

After all discussion on activities about composite sandwich panels in three analytical, experimental and numerical fields that done between 1990 until 2014, it seems that most studies connected to sandwich panels buckling were just according to special models. These researches almost continue with changing boundary conditions, dimensions, and even changing layers sequence. But just a few numbers of activities about comparison between specimens with production procedure and specimens with different materials and cores had been found. Hence, research about some questions such as:

1) How much product procedure can change mechanical behavior?

2) Which core in a sandwich panels has better behavior in buckling?

\section{Specimens Description}

In this paper four groups of sandwich panels were investigated. These groups are: sandwich panels with P.V.C. core which built by hand layup and V.I.P. methods, sandwich panels with Balsa core built by hand layup and V.I.P. method, sandwich panels with Balsa core which built by hand layup method (Figure 1, Figure 2). The specimens were tested in Mechanical Engineering Faculty, Rejaie University of Iran. All sandwich panels have the same dimensions. According Table 1 sandwich panels with P.V.C. core that made by hand Lay-up method are named by (A) and sandwich panels whit P.V.C. core that made by V.I.P. method are named by (B). Because of sandwich panel with Balsa core has just one specimen in each V.I.P. and hand lay-up method, their specimens called by their product methods. All specimens have $450 \mathrm{~mm}$ length and $150 \mathrm{~mm}$ wide and core thicknesses and layer details are explained at Table 2.

Table 1. Specimens information (Core, Product method, Dimensions, kind of fixtures that used in tests, notification about panels)

\begin{tabular}{|c|c|c|c|}
\hline Core & Product method & Dimension $(\mathrm{mm})$ & Fixture $^{*}$ \\
\hline \multirow{2}{*}{ P.V.C. } & Hand Layup & $150 \mathrm{~mm} \times 450 \mathrm{~mm}$ & S.S \& C.S \\
\cline { 2 - 4 } & V.I.P. & $150 \mathrm{~mm} \times 450 \mathrm{~mm}$ & S.S \& C.S \\
\hline \multirow{2}{*}{ Balsa } & Hand Layup & $150 \mathrm{~mm} \times 450 \mathrm{~mm}$ & S.S \& C.S \\
\cline { 2 - 4 } & V.I.P. & $150 \mathrm{~mm} \times 450 \mathrm{~mm}$ & S.S \& C.S \\
\hline
\end{tabular}

* Note: two lengths of specimens are free and one wide of specimens has simply support and the other wide of specimens has clamped support 
Table 2. Stacking sequences of layers for Balsa/P.V.C. sandwich panels.

\begin{tabular}{|c|c|c|c|c|c|c|c|}
\hline Core & Material & Layer No. & Commercial Name & Type & Orientation angle & $\begin{array}{l}\text { Weight } \\
{\left[\mathrm{g} / \mathrm{m}^{2}\right]}\end{array}$ & $\begin{array}{c}\text { Thickness } \\
{[\mathrm{mm}]}\end{array}$ \\
\hline \multirow{11}{*}{ Balsa } & \multirow{5}{*}{ Fiberglass } & 1 & Chopped Standard Mat & $\mathrm{EMC100P/E}$ & - & 100 & 0.1 \\
\hline & & 2 & Twill & Woven 200 & $0^{\circ}$ or $90^{\circ}$ & 200 & 0.15 \\
\hline & & 3 & Chopped Standard Mat & $\mathrm{EMC100P/E}$ & - & 100 & 0.1 \\
\hline & & 4 & Biax & MX 3500 & $\pm 45^{\circ}$ & 600 & 0.45 \\
\hline & & 5 & Chopped Standard Mat & $\mathrm{EMC100P/E}$ & - & 100 & 0.1 \\
\hline & Balsa & 6 & BALTEK & SB150 & - & $247\left[\mathrm{~g} / \mathrm{m}^{3}\right]$ & 10.0 \\
\hline & \multirow{5}{*}{ Fiberglass } & 7 & Chopped Standard Mat & $\mathrm{EMC100P/E}$ & - & 100 & 0.1 \\
\hline & & 8 & Biax & MX 3500 & $\pm 45^{\circ}$ & 600 & 0.45 \\
\hline & & 9 & Chopped Standard Mat & EMC100P/E & - & 100 & 0.1 \\
\hline & & 10 & Twill & Woven 200 & $0^{\circ}$ or $90^{\circ}$ & 200 & 0.15 \\
\hline & & 11 & Chopped Standard Mat & $\mathrm{EMC100P/E}$ & - & 100 & 0.1 \\
\hline \multirow{11}{*}{ P.V.C. } & \multirow{5}{*}{ Fiberglass } & 1 & Chopped Standard Mat & $\mathrm{EMC100P/E}$ & - & 100 & 0.1 \\
\hline & & 2 & Twill & Woven 200 & $0^{\circ}$ or $90^{\circ}$ & 200 & 0.15 \\
\hline & & 3 & Chopped Standard Mat & $\mathrm{EMC100P/E}$ & - & 100 & 0.1 \\
\hline & & 4 & Biax & MX 3500 & $\pm 45^{\circ}$ & 600 & 0.45 \\
\hline & & 5 & Chopped Standard Mat & $\mathrm{EMC100P/E}$ & - & 100 & 0.1 \\
\hline & P.V.C. & 6 & D.I.A.B. & $\mathrm{H}$ & - & $75\left[\mathrm{~g} / \mathrm{m}^{3}\right]$ & 10.0 \\
\hline & \multirow{5}{*}{ Fiberglass } & 7 & Chopped Standard Mat & $\mathrm{EMC100P/E}$ & - & 100 & 0.1 \\
\hline & & 8 & Biax & MX 3500 & $\pm 45^{\circ}$ & 600 & 0.45 \\
\hline & & 9 & Chopped Standard Mat & $\mathrm{EMC100P/E}$ & - & 100 & 0.1 \\
\hline & & 10 & Twill & Woven 200 & $0^{\circ}$ or $90^{\circ}$ & 200 & 0.15 \\
\hline & & 11 & Chopped Standard Mat & EMC100P/E & - & 100 & 0.1 \\
\hline
\end{tabular}

\section{Experimental Analysis}

\subsection{Boundary Conditions \& Fixtures}

As mentioned Table 1, two lengths of specimens are free, one wide of specimens has simply support and the other wide of specimens has clamped support. For starting buckling tests first of all, suitable fixtures are needed.
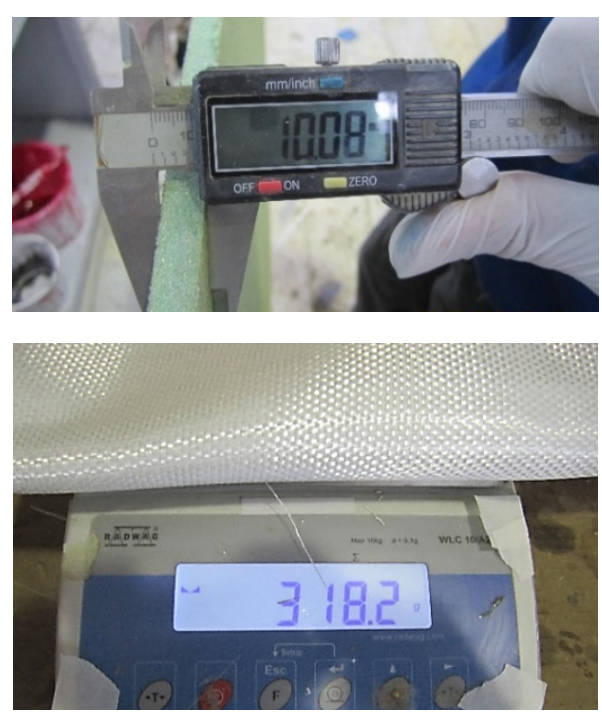
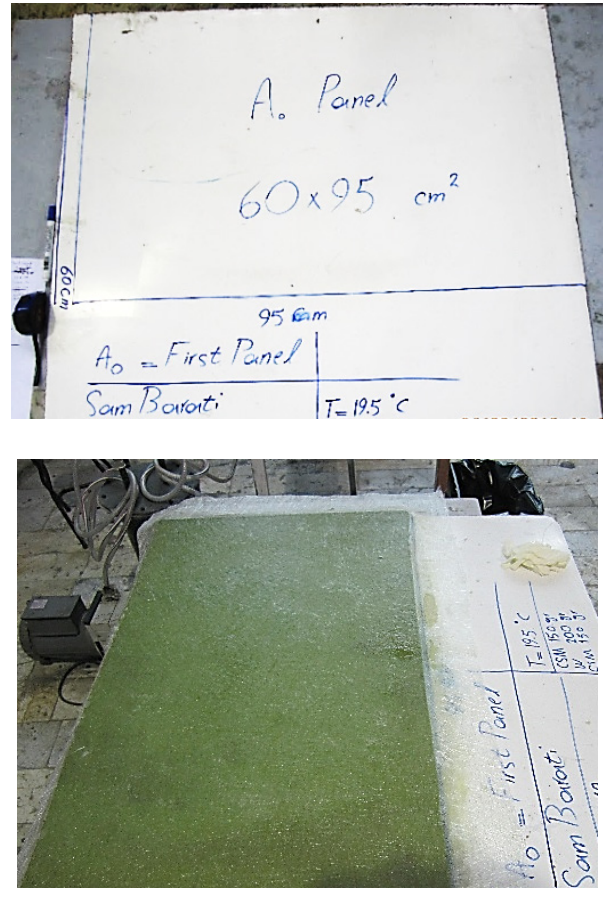

Figure 1. 6 Rectangular specimens P.V.C. core sandwich panels 

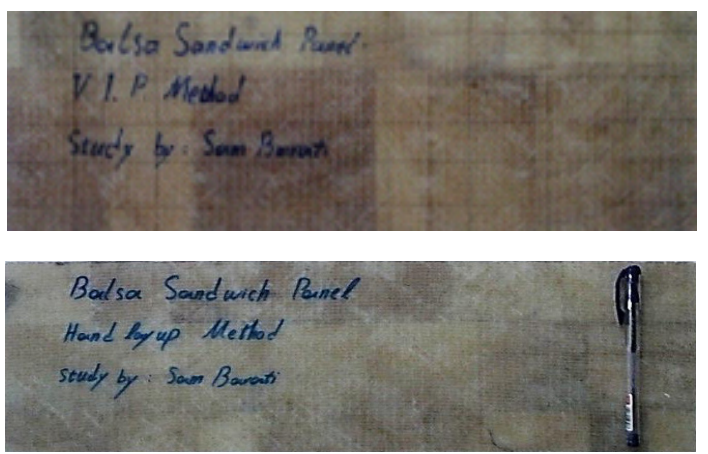

Figure 2. 2 rectangular specimens Balsa core sandwich panels

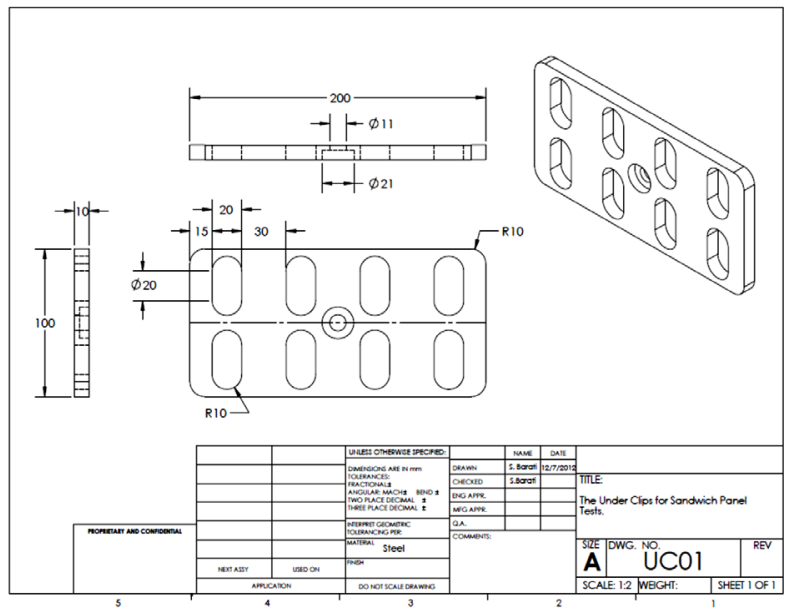

Figure 3. The base plate dimension in map.

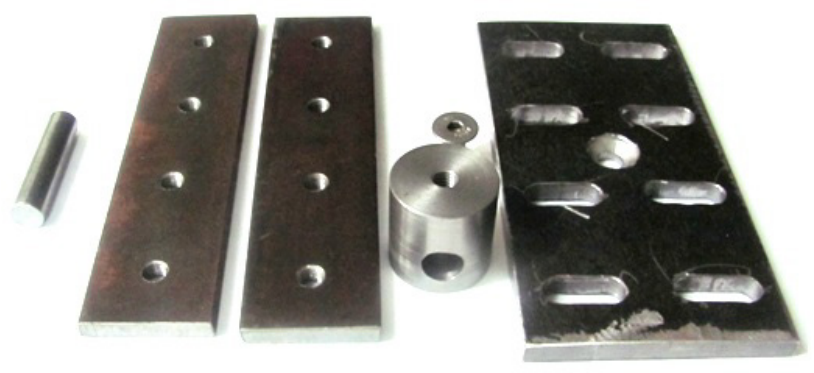

Figure 4. Axillary simply support fixture for buckling tests

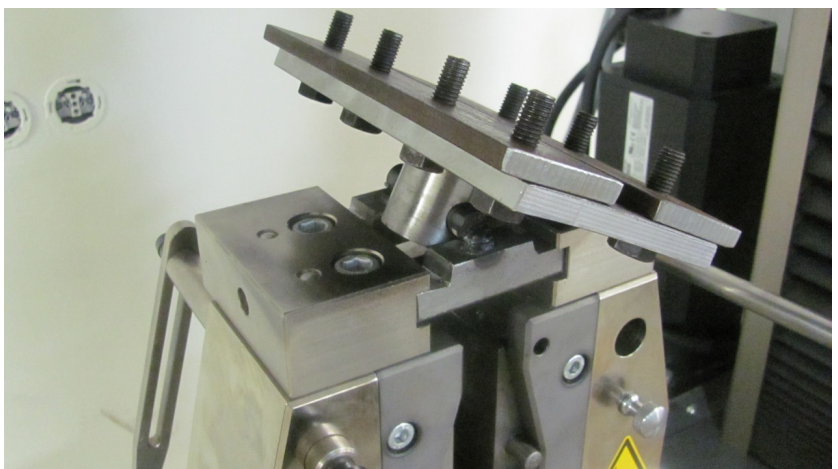

Figure 5. Assembled simply support fixture on instrument

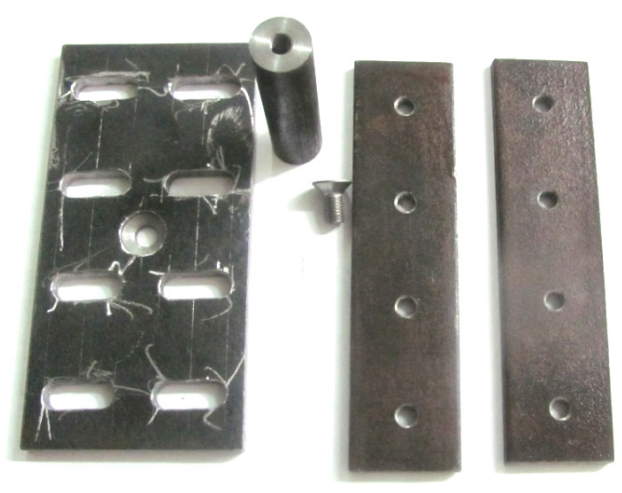

Figure 6. Axillary clamped support fixture for buckling tests

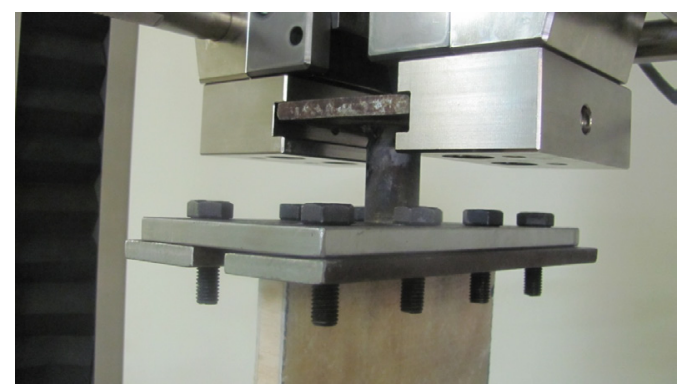

Figure 7. Assembled clamped support fixture on instrument

Base plate in both simply and clamped support fixtures as shown in Figure 3 contain oval holes. These holes give more advantages because of flexibility in assemble specimens with any thicknesses.

\subsection{Loading Condition}

The instrument load, applied inplane, along specimens length and load steps are according at sampling frequency $\mathrm{f}=20 \mathrm{~Hz}$ [14]. This load condition is equal for all specimens. The rather high acquisition frequency was selected to catch even dynamic and/or impulsive effects taking place during the post buckling phase of the tests, if any.

In sandwich panels with P.V.C. core, after an initial linear load vs. in plane displacement relationship, the panel starts moving out of its plane, introducing a stiffness reduction due to the progressive failure of the sandwich skins in way of the clamped edge. This phenomenon was clearly observed in four out of six tested specimens with P.V.C. core. Basically, in sandwich panels with P.V.C. core the failure is caused by the large and sudden out of plane displacements taking place in the post buckling equilibrium configuration, leading to high stress concentrations. However, beside the failures in way of clamped edges appearing during the collapse tests, in all tested specimens cracks first extended into the core starting from the mid span of the skin in compression and eventually leading to global collapse. The tensioned skin was practically undamaged at the end of the experimental tests. 
For two specimens, collapse occur without post buckling, means that core had been completely cut by shear stress.

For two specimens groups which made by hand lay-up and V.I.P. methods and contain P.V.C. core, as are shown in Figure 8 and Figure 9, buckling and post buckling behavior are approximately similar and the difference between them referee to buckling and post buckling loads and inplane displacement values.

In sandwich panels with Balsa core, after an initial linear load vs. in plane displacement relationship, the panel suddenly starts moving out of its plane. This phenomenon was clearly observed in both tested specimens with Balsa core. Basically, in sandwich panels with Balsa core the failure is caused by the large out of plane displacements which taking place in the post buckling equilibrium configuration, leading to high stress concentrations, but during failure, sudden out of plane did not happened. In both tested specimen cracks first occurred and extended at perpendicular load plane in the core and after that debonding between core and compression skin leading to global collapse. The tensioned skin just like specimens with P.V.C. core was practically undamaged at the end of the experimental tests. For two specimens groups which made by hand lay-up and V.I.P. methods and contain Balsa core, as are shown in Figure 10 and Figure 11, buckling and post buckling behavior are completely different and specifically difference between them referee to buckling and post buckling.

From specimens with P.V.C. core which tests, results the following considerations can be drawn out:

I A fairly linear relationship is confirmed up to collapse load by all specimens (Figure 8),

II The ultimate load does not seem to be depending on the fabrication method as for all specimens the collapse load is about $10 \mathrm{kN}$, except for specimen B1 that show slightly lower strength (Table 3),

III The infusion made specimens are approximately $15 \%$ stiffer in terms of elastic compressive modulus (Table 4). 
Table 3. collapse load/displacement of specimens

\begin{tabular}{|c|c|c|c|c|c|c|c|c|c|c|c|}
\hline Type & Core & $\begin{array}{l}\text { Product } \\
\text { Method }\end{array}$ & Name/No & $\begin{array}{c}\text { Buckling } \\
\text { Stress [MPa] }\end{array}$ & $\begin{array}{c}\text { Post Buckling } \\
\text { Stress [MPa] }\end{array}$ & $\begin{array}{l}\text { Buckling } \\
\text { Load }[\mathrm{KN}]\end{array}$ & $\begin{array}{c}\text { Post Buckling } \\
\text { Load }[\mathrm{KN}]\end{array}$ & $\begin{array}{l}\text { Buckling } \\
\text { Strain }\end{array}$ & $\begin{array}{c}\text { Post Buckling } \\
\text { Strain }\end{array}$ & $\begin{array}{c}\text { Buckling } \\
\text { Displacement } \\
{[\mathrm{mm}]}\end{array}$ & $\begin{array}{c}\text { Post Buckling } \\
\text { Displacement [mm] }\end{array}$ \\
\hline Spec. & $\mathrm{PVC}$ & Hand Layup & A1 & 4.580374 & - & 10.0227 & - & 1.3653 & - & 0.6068 & - \\
\hline Spec. & $\mathrm{PVC}$ & Hand Layup & $\mathrm{A} 2$ & 4.302609 & 4.132285 & 9.4149 & 9.0422 & 1.3356 & 1.7520 & 0.5936 & 0.7787 \\
\hline Spec. & PVC & Hand Layup & A3 & 4.219892 & 3.733096 & 9.2339 & 8.1687 & 1.4469 & 1.5970 & 0.6431 & 0.7098 \\
\hline Spec. & $\mathrm{PVC}$ & V.I.P. & B1 & 3.711983 & 3.264854 & 8.1225 & 7.1441 & 0.8394 & 1.0192 & 0.3731 & 0.453 \\
\hline Spec. & $\mathrm{PVC}$ & V.I.P. & $\mathrm{B} 2$ & 4.901508 & - & 10.7254 & - & 1.2426 & - & 0.5523 & - \\
\hline Spec. & $\mathrm{PVC}$ & V.I.P. & B3 & 4.174924 & 4.174924 & 9.1355 & 9.1355 & 1.3605 & 1.3659 & 0.6047 & 0.6071 \\
\hline $\begin{array}{l}\text { FEM } \\
\text { Model }\end{array}$ & $\mathrm{PVC}$ & V.I.P. & - & 5.1428 & - & 11.2114 & - & 0.9043 & - & 0.4021 & - \\
\hline $\begin{array}{l}\text { FEM } \\
\text { Model }\end{array}$ & $\mathrm{PVC}$ & Hand Layup & - & 3.9904 & 3.9771 & 8.6991 & 8.6701 & 1.3152 & 1.6440 & 0.5848 & 0.731 \\
\hline $\begin{array}{l}\text { FEM } \\
\text { Model }\end{array}$ & Balsa & V.I.P. & V.I.P. & 9.790732 & - & 21.4231 & - & 0.384576 & - & 5.848 & - \\
\hline $\begin{array}{l}\text { FEM } \\
\text { Model }\end{array}$ & Balsa & Hand Layup & Hand Layup & 9.746172 & 9.742242 & 21.3256 & 21.317 & 0.552607 & 0.412903 & 4.0698 & 5.4468 \\
\hline Spec. & Balsa & V.I.P. & V.I.P. & 10.32261 & 7.593711 & 22.5869 & 16.6158 & 0.647903 & 0.335647 & 3.4712 & 6.7005 \\
\hline Spec. & Balsa & Hand Layup & Hand Layup & 14.13729 & 9.610667 & 30.9338 & 21.0291 & 0.484385 & 0.479296 & 4.643 & 4.6923 \\
\hline
\end{tabular}

Table 4. Buckling behavior comparison for all specimens and FEM models.

\begin{tabular}{|c|c|c|c|c|c|c|c|}
\hline Type & Core & Product Method & Name/No. & $\begin{array}{c}\text { Buckling Stress } \\
(-) \\
\text { Post Buckling Stress [MPa] }\end{array}$ & $\begin{array}{c}\text { Buckling Load } \\
(-) \\
\text { Post Buckling Load }[\mathrm{KN}]\end{array}$ & $\begin{array}{l}\text { Post Buckling Strain (-) } \\
\text { Buckling Strain }\end{array}$ & $\begin{array}{c}\text { Post Buckling Displacement } \\
\text { (-) Buckling Displacement } \\
{[\mathrm{mm}]}\end{array}$ \\
\hline Spec. & $\mathrm{PVC}$ & Hand Layup & $\mathrm{A} 1$ & $\times$ & $\times$ & $x$ & $x$ \\
\hline Spec. & PVC & Hand Layup & A2 & 0.170324 & 0.3727 & 0.4164 & 0.1851 \\
\hline Spec. & $\mathrm{PVC}$ & Hand Layup & A3 & 0.486796 & 1.0652 & 0.1501 & 0.0667 \\
\hline Spec. & $\mathrm{PVC}$ & V.I.P. & $\mathrm{B} 1$ & 0.447129 & 0.9784 & 0.1798 & 0.0799 \\
\hline Spec. & PVC & V.I.P. & $\mathrm{B} 2$ & $\times$ & $x$ & $\times$ & $x$ \\
\hline Spec. & $\mathrm{PVC}$ & V.I.P. & B3 & $x$ & $x$ & 0.0054 & 0.0024 \\
\hline FEM Model & $\mathrm{PVC}$ & V.I.P. & - & $x$ & $x$ & $x$ & $x$ \\
\hline FEM Model & PVC & Hand Layup & - & $x$ & 0.029 & 0.3288 & 0.1462 \\
\hline FEM Model & Balsa & V.I.P. & V.I.P. & 0.0133 & $x$ & $x$ & $x$ \\
\hline FEM Model & Balsa & Hand Layup & Hand Layup & $x$ & 0.0086 & -0.1397 & 1.377 \\
\hline Spec. & Balsa & V.I.P. & V.I.P. & 0.00393 & 5.9711 & -0.31226 & 3.2293 \\
\hline Spec. & Balsa & Hand Layup & Hand Layup & 2.728899 & 9.9047 & -0.00509 & 0.0493 \\
\hline
\end{tabular}


And from specimens with Balsa core which tests, results the following considerations can be drawn out:

I. A fairly linear relationship is confirmed up to collapse load for V.I.P. specimen, but in hand lay-up specimen there are two different linear relationships to collapse load,

II. The ultimate load between two fabrication methods are totally different (Figure 10 and Figure 11),

III. Post buckling behavior happen completely different in hand lay-up specimen (Figure 10).

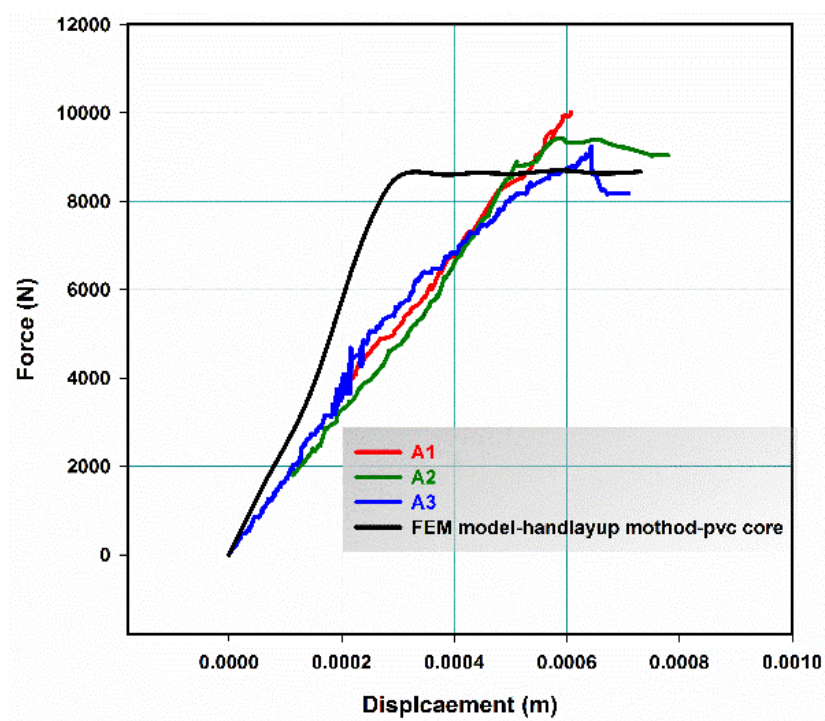

Figure 8. Buckling and Post-Buckling behavior for sandwich panels with P.V.C. core that made by hand lay-up method

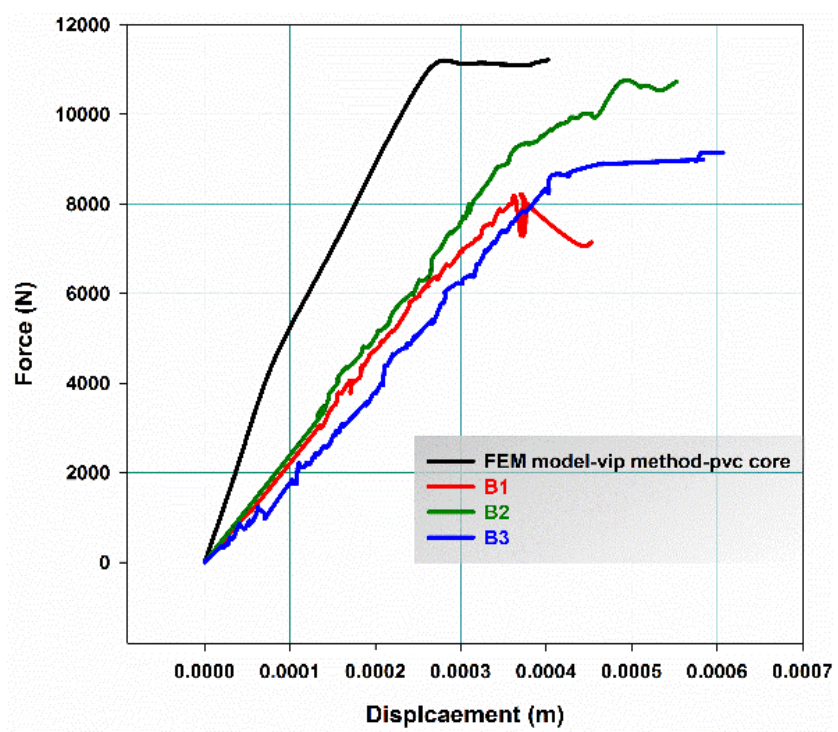

Figure 9. Buckling and Post-Buckling behavior for sandwich panels with P.V.C. core that made by V.I.P. method

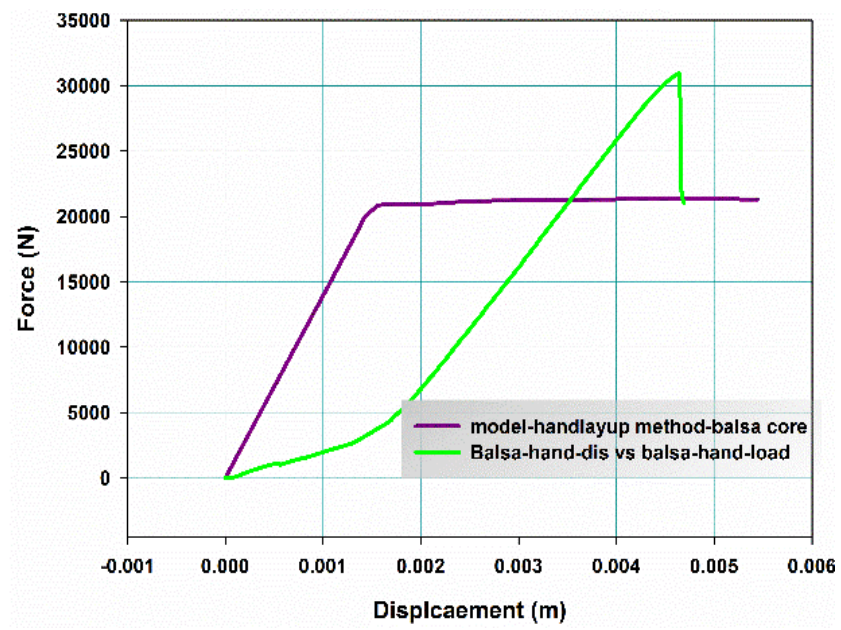

Figure 10. Buckling and Post-Buckling behavior for sandwich panel with Balsa core that made by hand lay-up method

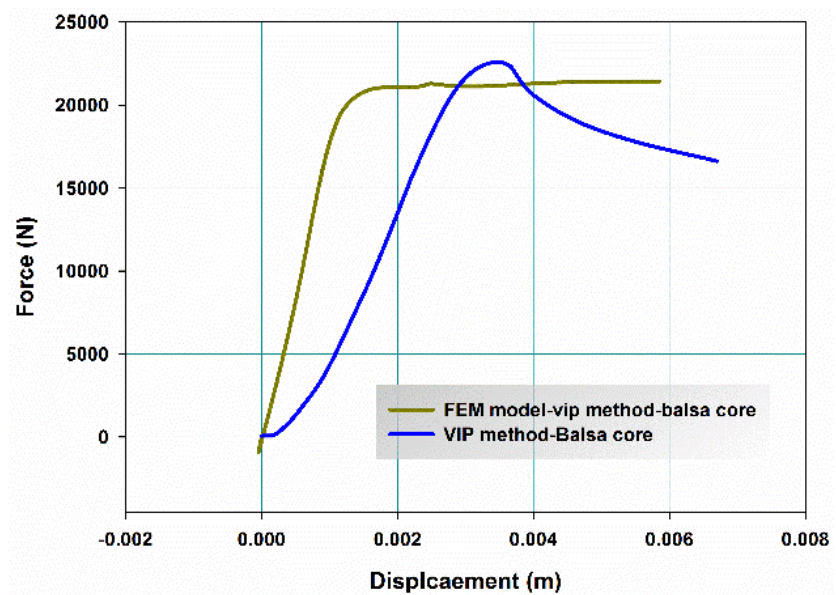

Figure 11. Buckling and Post-Buckling behavior for sandwich panel with Balsa core that made by V.I.P. method

\section{Numerical Modeling}

For modeling in this activity, finite element software was used. Two different methods for determined the best model were used [13]. First of all, load controlled method was chosen to define buckling load and displacement vs. load happened in models. At this step, four models were investigated. As mentioned, models should have the best similarity with experimental tests and load controlled method can helps to choose the best model. After choosing best model, displacement controlled method was used to show both buckling and post buckling behaviors in model at the same time. 
Different modeling strategies were used to simulate the structural behavior of the sandwich panels under compressive inplane loading and the most challenging task for model is the correct simulation which prediction buckling load and inplane displacement and after all, has acceptable similarity in post buckling confine.

I. MODEL (A): All layers including core modeled as 2D layered that used shell 181 model: this model completely ignores the Poisson's effect of the core in sandwich panel, therefore with large displacement, outcome is leading to an over-estimated critical post buckling stiffness much greater than of the experimental tests [13].

II. MODEL (B): For more analysis a trying was done by create model B which built by shell 281 that had same layers with model (A) but in model, more nods had been used. This capability let model to show better motion and displacement. In model B, post buckling stiffness was much greater than the experimental tests too [13].

III. MODEL (C): To overcome the problem above and getting Poisson's effect of the core, adding more elements placed on the agenda. Element solid 185 because of has plasticity, hyper elasticity, stress stiffening, creep, large deflection, and large strain capability was suitable. It also has mixed formulation capability for simulating deformations of nearly incompressible elastic-plastic materials, and fully incompressible hyper elastic materials. In this model, core was modeled by solid 185 element and skins were modeled by shell 181 . Each node of the skin shell elements were attached to node of core solid element. This model didn't estimate the critical load correctly and in the pre-buckling phase the stiffness was upper-estimated and buckling load didn't in the load test range, Figure 12.

IV. MODEL (D, Combined model): To overcome upper-estimating buckling load and reach to debonding and shrinkage, an especial connection in middling of skin and core is needed. For this reason link180 element is used. In this combined model, core was modeled by solid 185 element and skins were modeled by shell 181 too. Model D gave better results, but until now, there are some differences with experimental data, even in the post-buckling phase, where the specimen clamped edge do not suffer early failure. Note that, model D is more time consuming and computations requires more computer resources also because of DOF coupling between shell and solid elements, Figure 13 [13].

V. MODEL (E): With using model D, predicting buckling point was acceptable but gain the best model has been continued. The difference of numerical result in model $\mathrm{D}$ and experimental data was because of ignored three layers of Chopped Standard Mat in $1^{\text {st }}, 3^{\text {rd }}$ and $5^{\text {th }}$ of layers. The defect in model $\mathrm{D}$ is that chopped layers can't model as $2 \mathrm{~d}$ layer or $3 \mathrm{~d}$ orthotropic layer. At model $\mathrm{E}$ which built according model $\mathrm{D}$, chopped layers had $2 \mathrm{D}$ isotropic property between layers and matrix property along $\mathrm{z}$ axis (it means that $\mathrm{z}$ direction is perpendicular with inplane load).

To determine proper finite element model, in analysis according load controlled method, V.I.P. specimens with P.V.C. core were chosen because of numbers of tests and accuracy built method. Finite element results for models as shown in Figure 14 are completely different. Model (A) cannot reach to goal and has huge inplane displacement, model (B) had the same manner and completely similar with model (A). Model (C) stiffness is so big that under loading, failure didn't happened and inplane displacement is so small. Against the other models model (D) has better behavior for inplane compressing loading and buckling. But inplane displacement for model (D) is so great which it probably depend on neglecting chopped layers. At last, model (E) with considering chopped layers has the best results for buckling and post buckling behavior.

So with analyses finite element models, model (E) has chosen. After determine the best model, buckling and post buckling are investigated with displacement controlled method together. There are six specimens with P.V.C. core and to reach better agreements, comparing finite element analysis with experimental data and average of the experimental data is suitable.

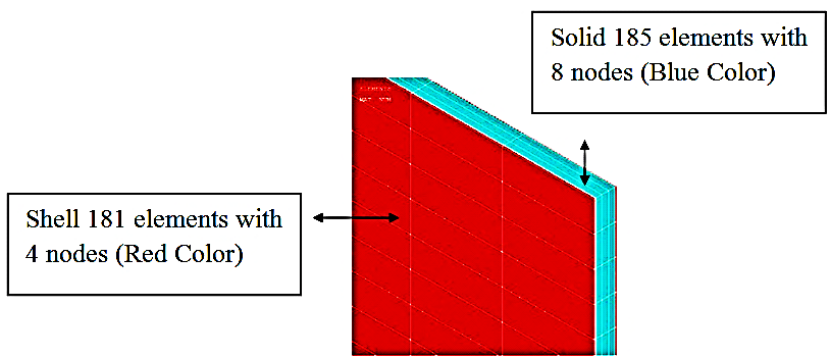

Figure 12. Finite element model (MODEL C)

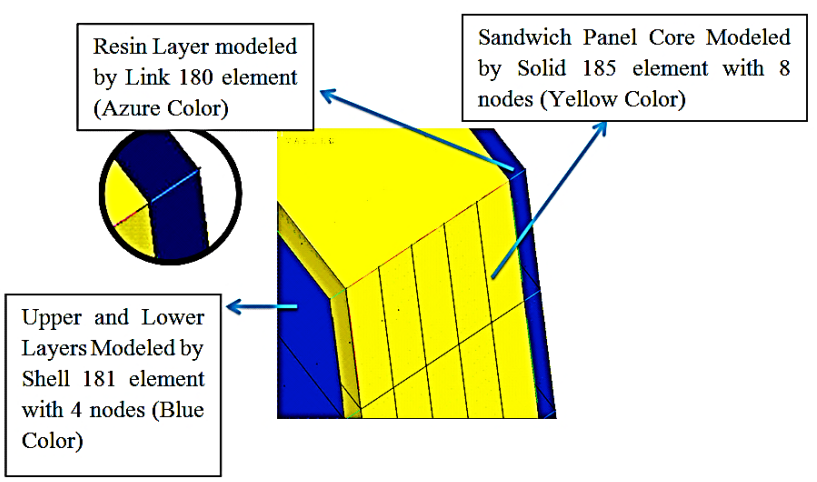

Figure 13. Finite element model (MODEL D, Combined model) 


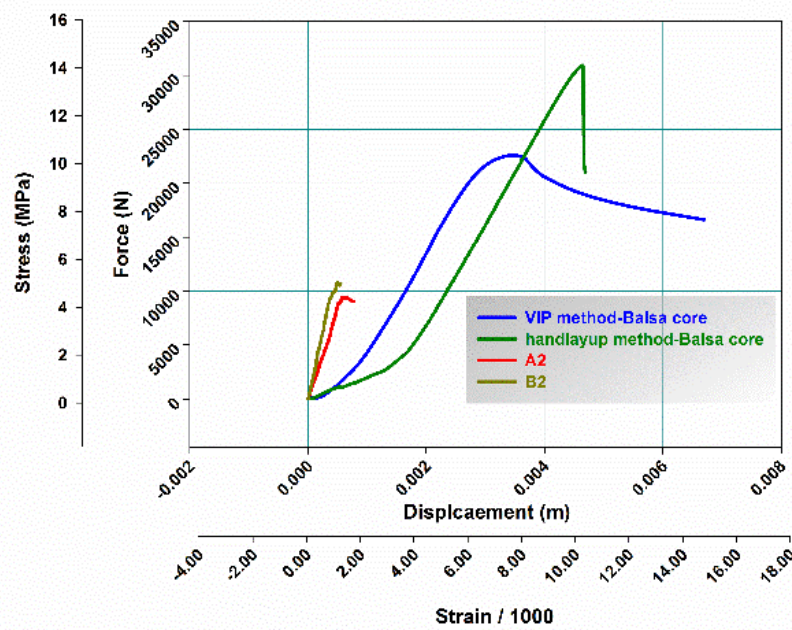

Figure 14. Inplane buckling load - Displacement about ANSYS finite element models comparing with the average of Hand lay-up and V.I.P. specimens contain P.V.C. core.

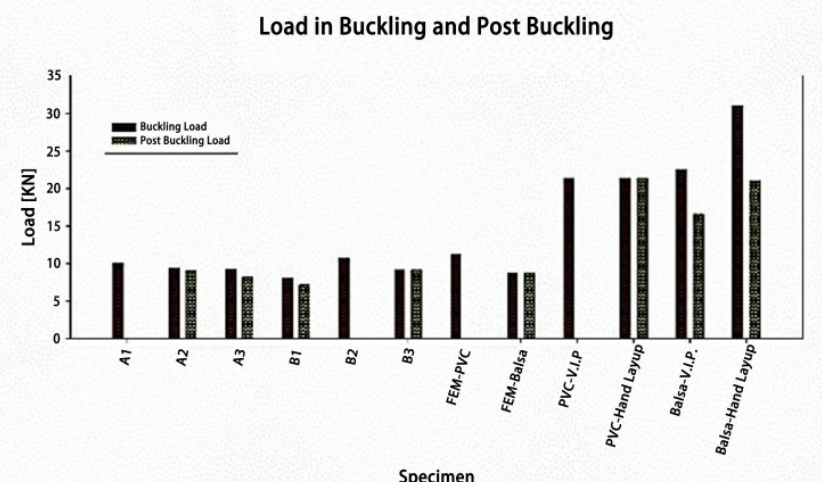

Figure 15. Inplane load of specimens and FE models in buckling and post buckling behaviors.

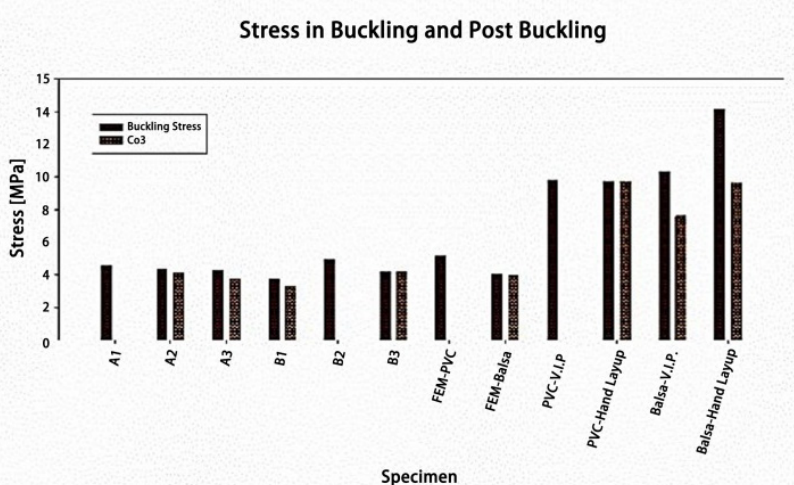

Figure 16. Stress of specimens and FE models in buckling and post buckling behaviors.

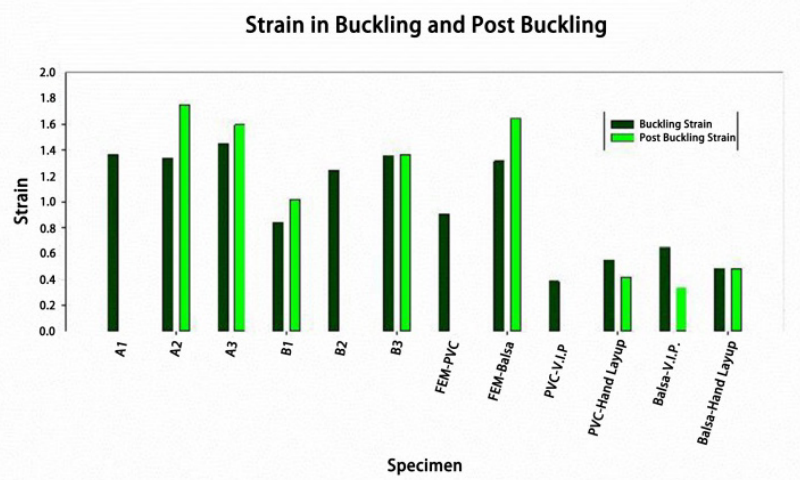

Figure 17. Strain of specimens and FE models in buckling and post buckling behaviors. 

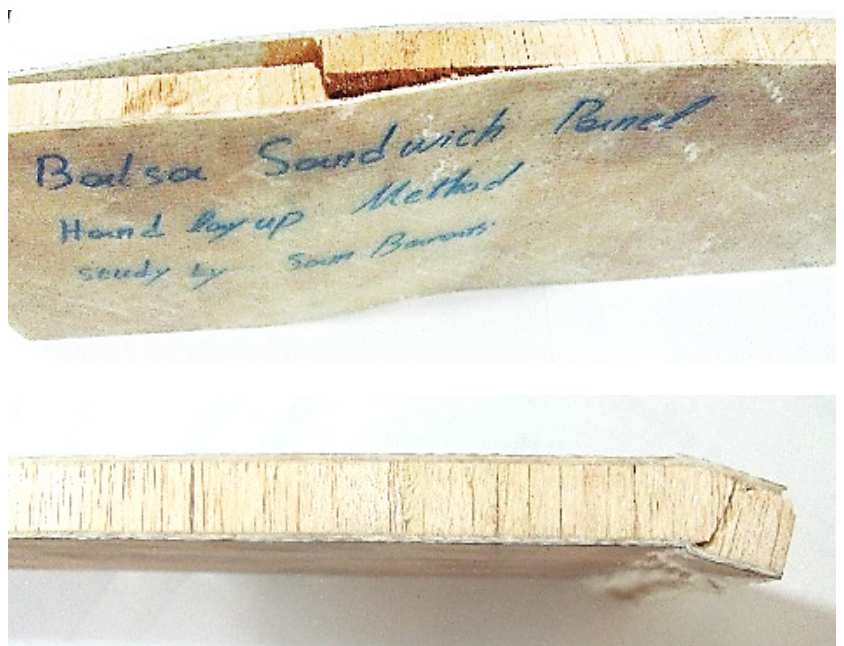

Figure 18. Different failure modes observed during specimens tests Hand lay-up specimen with Balsa core (on the top), V.I.P. specimen with Balsa core (on the bottom).

\section{Conclusions}

In the present paper two different fabrication technologies for sandwich panels with different cores are compared to assess strength of laminates under compressive loads. The experimental sets of specimens were designed in order to show buckling, post buckling and ultimate compressive failure.

In specimens with P.V.C. cores, no significant difference has been noted depending on the fabrication method from the tests in terms of ultimate strength, but different failure modes were observed depending on localized adhesion strength, on the other hand, in specimens with Balsa cores significant difference has been noted depending on the fabrication method from the tests in terms of ultimate strength, and different failure modes were observed depending on localized adhesion strength (Figure 8 \& Figure 9).

In specimens with Balsa cores, significant difference has been noted. Different failure modes were observed in the tests in terms of ultimate strength depending on localized adhesion strength due to initial core deflection, on the other hand significant difference has been noted depending on the fabrication method from the tests in terms of ultimate strength, and different failure modes were observed (Figure 18).

A parallel work is carried out to obtain a reliable finite element model to predict buckling and post buckling behaviors of sandwich panels with low stiffness and soft compressible P.V.C. and high stiffness and strength compressible Balsa cores: five modeling approaches were tested starting from a basic $2 \mathrm{D}$ shell model up to a 3D model with newly proposed shell to solid coupling constraints with link element (Model E).

For two similar sandwich panels with different cores
(Balsa/P.V.C.), strain in panel with Balsa core under inplane load is about $50 \%$ of panel with P.V.C. core and the average stress for panels with P.V.C. core is about $50 \%$ of average stress for panels with Balsa core.

The final result can be considered satisfactory and the experimental validation leads to consider the strategy of connecting core to skins in modeling sandwich by using solid elements appropriately coupled with the shells elements throw link elements as a quite reliable one and worth of further investigations.

Another important consideration arising from the different models presented in this paper is that the transversal stresses are not negligible in buckling problems where low core stiffness modifies the geometrical shape of the tested panels.

\section{Acknowledgements}

The authors wish to thanks Mr. Mojtaba Pakbaz head of A.S.A.K. Co. for helping us to test sandwich panels.

\section{REFERENCES}

[1] Elastic buckling behavior of the surface material in sandwich structure. Moe Yamanaka, Kikuo Ikarashi, Toru Inaba. 2-3, Berlin: Proceedings of Eurosteel 2017, 2017, Vol. 1.

[2] Buckling optimisation of sandwich cylindrical panels. M. Abouhamzeh, M. Sadighi. 1, Kluyerweg : De Gruyter open, 2016, Vol. 3. 10.1515/cls-2016-0011.

[3] Buckling of axially loaded sandwich composite panels with reinforced calcium silicate faces and polyurethane cores. Zhirong Tang, Xiaoxiong Zha, Jinquan Ma. 17, China : SAGE Journals, 2015, Vol. 34. $10.1177 / 0731684415592057$.

[4] Buckling Testing and Analysis of Honeycomb Sandwich Panel Arc Segments of a Full-Scale Fairing Barrel. Evan Pineda, David E. Myers, Daniel N. Kosareo, Thomas G. Gyekenyesi. 55, Cleveland: Structures Structural Dynamics and Materials Conference, 2014, Vol. 2. 10.2514/6.2014-1052.

[5] Studies on buckling behavior of honeycomb sandwich panel. Jeyakrishnan, P., Chockalingam, $\mathrm{Kn}$ and Narayanasamy, R. 5-8, Berlin: International Journal of Advanced Manufacturing Technology, 2013, Vol. 65. 0268-3768.

[6] Accurate buckling load calculations of a thick orthotropic sandwich panel. Ji, Wooseok and Waas, Anthony M. 10, New York: ELSEVIER SCI LTD, 2012, Vol. 72 0266-3538.

[7] Buckling of anisotropic sandwich panels containing holesPart II - wrinkling. Hadi, B. K. and Matthews, F. L. 1, Bandung: Composite Structures, 2001, Vol. 54. 0263-8223.

[8] Predicting the buckling load of anisotropic sandwich panels: an approach including shear deformation of the faces. B.K. 
Hadi, F.L. Matthews. 3, London: Composite Structures, 1998, Vol. 42. 0263-8223.

[9] Buckling of sandwich panels with different boundary conditions - A comparison between FE-analysis and analytical solutions. Heder, Mats. 4, Göteborg : Composite Structures, 1991, Composite Structures, Vol. 19. 0263-8223.

[10] Buckling Testing and Analysis of Honeycomb Sandwich. Kellas, Evan J. Pineda and David E. Myers and Daniel N. Kosareo and Sotiris. Hanover: s.n., 2014. 21076-1320.

[11] Comparative studies of localized buckling in sandwich struts with different core bending models. M. Ahmer Wadee, Stylianos Yiatros, Marios Theofanous. 2, New York: Non-Linear Mechanics, Elsevier, 2010, Vol. 45. 10.1016.

[12] Experimental, numerical, and analytical results for buckling and post-buckling of orthotropic rectangular sandwich panels Original Research Article. Boyle, M. P., et al. 3-4, Laurel: Composite Structures, 2001, Vol. 52. 0263-8223.

[13] S. Barati Nardin, M. R. Khedmati. Investigation into buckling and post buckling behavior of sandwich panels with Balsa or PVC core made by hand layup and vacuum bag infusion procedures. [Master of Science Thesis] Tehran, Tehran, Iran : Maritime School, Amirkabir University, 2014. $10.1177 / 0021998312451763$

[14] Buckling behavior of FRP sandwich panels made by hand layup and vacuum bag infusion procedure. Gaiotti, Marco. London: Taylor \& Francis Group, 2012.978-0-415-620819.

[15] Post-buckling and debond propagation in sandwich panels subject to in-plane compression. Aviles, F. and Carlsson, L. A. 5, NEY YORK: Engineering Fracture Mechanics, 2007, Vol. 74. 794-806.

[16] Finite-element buckling analysis of sandwich columns containing a face/core debonds. Veedu, Vinod P. and Carlsson, Leif A. 2, Florida: Composite Structures, 2005, Vol. 69. 0263-8223.

[17] Post-buckling behavior of composite panels in the presence of unstable delaminations. Gaudenzi, P., Perugini, P. and Riccio, A. 3, Roma: Composite Structures, 2001, Vol. 51. 0263-8223. 